NASA Technical Memorandum 82881

\title{
Performance of a 2D-CD Nonaxisymmetric Exhaust Nozzle on a Turbojet Engine at Altitude
}

David M. Straight and Richard R. Cullom

Lewis Research Center

Cleveland, Ohio

Prepared for the

Eighteenth Joint Propulsion Conference

cosponsored by the AIAA, SAE, and ASME

Cleveland, Ohio, June 21-23, 1982

\section{NRSA}




\title{
PERFORMANCE OF A 20-CD NONAXISYMMETRIC EXHAUST NOZZLE ON A
}

\author{
TURBOJET ENGINE AT ALTITUDE \\ David M. Straight* and Richard R. Cullom \\ National Aeronautics and Space Administration \\ Lewis Research Center \\ Cleveland, Ohio:
}

芒

\section{ABSTRACT}

Many studies and model tests on nonaxisymmetric (2D) exhaust systems have been reported in recent years which show promising payoffs for advanced military aircraft application. Thrust and cooling performance data obtained with 20 exhaust systems in the full scale engine environment, however, are scarce.

This paper presents baseline thrust and cooling data obtained with a 2D-CD versatile research exhaust nozzle mounted on a turbojet engine in an altitude chamier. The tests covered a range of nozzle pressure ratios, nozzle throat areas, and internal expansion area ratios. The thrust data obtained show good agreement with theory and scale model results after correcting the data for leakage and bypass coolant flows. Additional work is needed to improve predictability of cooling performance.

\section{NOMENCLATURE}

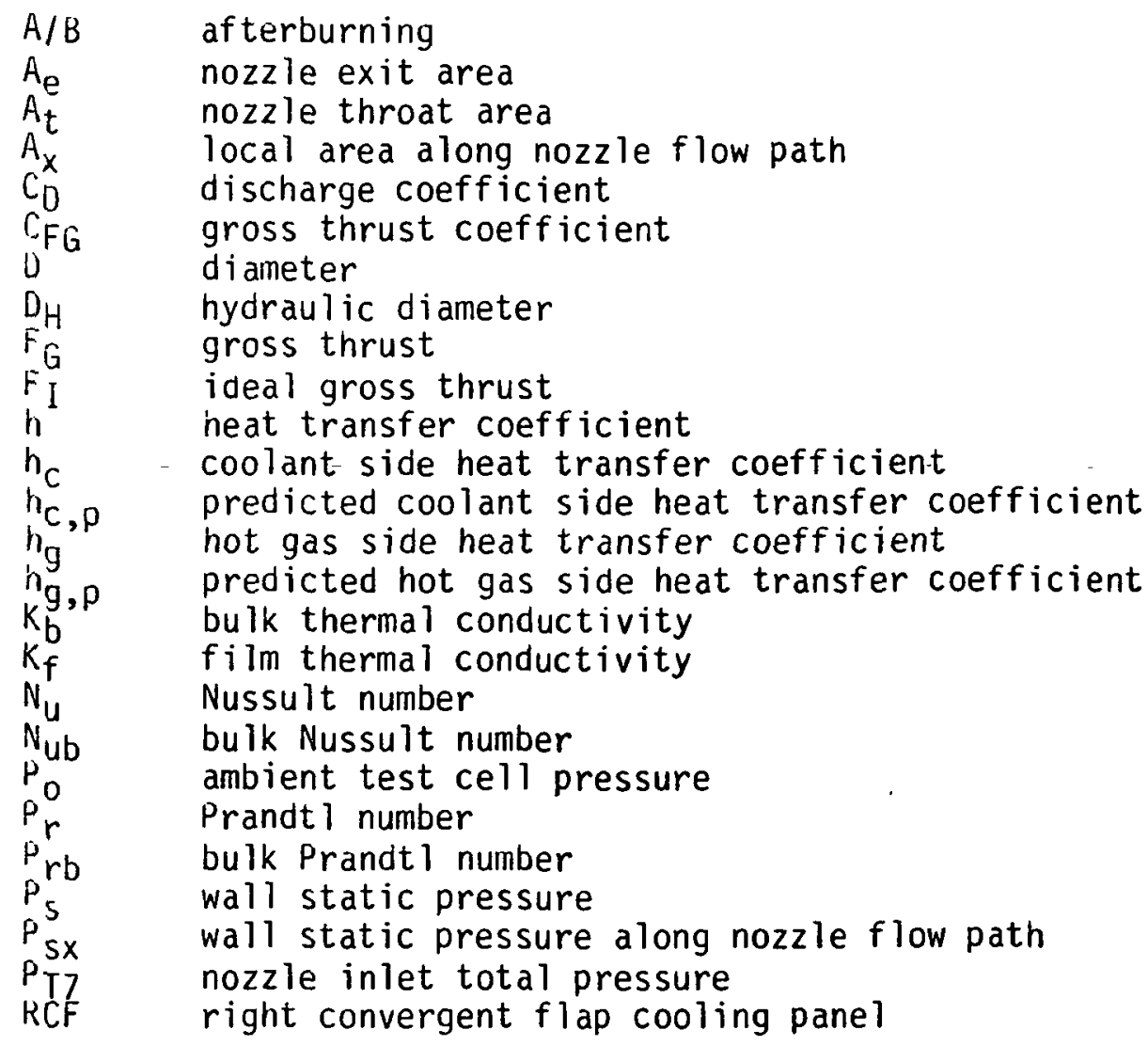

\#Pember, AIAA. 
ROFI right divergent flap cooling panel number 1

RDF2 right divergent flap cooling panel number 2

RDF3 right divergent flap cooling panel number 3

$\mathrm{Re}_{\mathrm{b}} \quad$ bulk Reynolds number

Ref film Reynolds number

SERN single Expansion Ramp Nozzle

$T_{G} \quad$ hot gas temperature

$\checkmark$ hot gas stream bulk velocity

$X \quad$ axial distance along nozzle flowpath

$Y \quad$ across-stream distance along width of nozzle flaps

$Z \quad$ across-stream distance along nozzle sidewalls

$\alpha_{c} \quad$ convergent flap angle to engine centerline

$a_{d} \quad$ divergent flap angle to engine centerline

$\gamma$ specific heat ratio

$\mu_{f} \quad$ film viscosity

of film density

2D-CD Two-Dimensional Convergent-Divergent

\section{INTRODUCTION}

Nonaxisymmetric exhaust nozzles have potential payoffs for advanced fighter aircraft which include improved integration with the airframe to reduce drag and increase lift, improved manueverability in combat situations through vectoring and reversing, and increased flexibility for short takeoff and landing (STOL) operations. A bibliography and summary of 82 publications on nonaxisymmetric nozzles up to 1979 is documented (ref. 1). Additional experimental data currently available includes scale model tests with several nonaxisymmetric nozzle concepts and design variables. Both internal performance obtained in static rig tests (refs. 2 to 4 ) and installed performance with wind tunnel models have been published (refs. 5 to 9). Paper studies are available on integrating nonaxiysmmetric nozzles with several different aircraft (ref. 1) in which payoff benefits were determined analytically based on model test results. There is, however, a paucity of full scale engine data to confirm the high performance potential indicated by the model tests. Favorable results have been obtained in the full scale ADEN program (ref. 10) at sea level static test conditions. Tests over the full operating range at altitude, however, remain to be done.

NASA Lewis Research Center has had an ongoing program on exhaust nozzle performance and cooling with full scale research hardware designed for testing in the engine environment including afterburning temperatures and pressure loads over the full range of simulated flight conditions.

A low-aspect-ratio versatile 2DCD nonaxisymmetric research exhaust nozzle was designed and built by a contractor for testing on a j85-13 full scale turbojet engine. The design incorporated many variable features so that parametric data on the effect of the variables could be obtained. The variables included variable throat area for afterburning, variable area ratio for a wide range of nozzle pressure ratios, vectoring by two methods (flap vectoring or pivoting the nozzle throat), thrust reversing, and replacable panels to study various cooling schemes on the convergent and divergent flaps. Single expansion ramp nozzle (SERN) configurations can also be investigated by removing one of the divergent flaps. The design philosophy, to keep costs low, was to use boilerplate support structure but realistic flight weight internal parts and realistic flow paths. Simple leaf-type low cost seals were used through- 
out to prevent leakage. The nozzle was extensively instrumented for obtaining internal thrust performance and heat transfer data.

This paper presents the baseline dry thrust performance obtained with the nozzle in the normal cruise position (nonvectored). Nonafterburning thrust data were obtained for three nominal throat areas $\left(710,903\right.$, and $\left.1129 \mathrm{~cm}^{2}\right)$. The first area is the dry cruise throat area, the second corresponds to a partial afterburning operating point. The largest area is that required for maximum afterburning conditions. These nonafterburning test were conducted over a range of internal area ratios (1.2 to 2.3) and operating nozzle pressure ratios (1.5 to 14.0$)$ in the PSL-3 altitude test facility at NASA Lewis Research Center. The maximum performance potential of the nozzle was determined by correcting the measured thrust coefficients for seal leakage and cooling airflows that bypassed the nozzle throat. The corrected thrust data is compared with simple one dimensional theory and scale model data for similar geometries (ref. 2). To complete the documentation of parameters that affect internal thrust performance, several plots of typical internal wall static pressure profiles are presented and compared with one-dimensional theory. Preliminary data on some of the heat transfer coefficient results obtained are also included in the paper and compared with predicted values from existing correlations.

The paper concludes with a brief discussion of possible solutions to a seal leakage problem that became apparent during the test.

\section{APPARATUS \\ Engine and Installation}

The engine used for this investigation was a J85-13, afterburner equipped turbojet. At sea level static conditions, rated dry thrust is 12900 newton $(2900 \mathrm{lb})$ at an airflow of $20 \mathrm{~kg} / \mathrm{sec}(44 \mathrm{ib} / \mathrm{sec})$. For these tests, the standard axisymmetric, variable area, exhaust nozzle was replaced with a two-dimensional, convergent-divergent nozzle. The standard 385 variable area nozzle control was replaced by a manual $2 D-C D$ nozzle area control which was independent of the engine main fuel control. The engine installation in the altitude test chamber was a conventional direct-connect type (fig. 1). In this test installation, the $20-C D$ nozzle has been rotated $90^{\circ}$ around the engine centerline from a typical airframe installation.

\section{Nozzle}

The two-dimensional, convergent-divergent exhaust nozzle is capable of variable internal and/or external expansion, also jet deflection by pivoting and/or flap vectoring and thrust reversal. The versatility of the design is shown in figure 2. The nozzle was designed and fabricated under contract by General Electric. Design features of this hardware include a fixed transition section, two pivotable reverser-blocker doors, 50 percent cutback sidewalls, interchangeable flap cooling panels and a pivotable nozzle body with movable convergent and divergent flaps, figure 3. All movable components of the nozzle were sealed against hot gas leakage with simple elastic leaf sheet metal seals. Location of these seals is indicated in figure 3 . The movable convergent and divergent flaps provide throat area and nozzle expansion area ratio variation. With the movable flaps, the nozzle throat area could be varied from $568 \mathrm{~cm}^{2}$ (88 in.2) to $1290 \mathrm{~cm}^{2}$ (200 in.2). For the dry cruise condition at flight Mach number of 0.9 and aititude of $4570 \mathrm{~m}$ ( $15000 \mathrm{ft}$ ) the 
nozzle throat had an aspect ratio of 4.0 . The width of the exhaust gas flowpath between the sidewalls through the rectangular nozzle was constant at $53.67 \mathrm{~cm}(21.13 \mathrm{in.})$. The test nozzle had an overal1 maximum length of $244 \mathrm{~cm}$ ( 96.2 in.) including the transition section. When nozzle body pivoting and divergent flap vectoring are combined, the exhaust jet can be deflected a maximum of $\pm 30^{\circ}$.

The various parts of the nozzle assembly were cooled by the different methods indicated in figure 4. Each convergent flap had one replaceable cooling panel and each divergent flap had three replaceable panels. Hardware was available for three different cooling schemes on the nozzle flaps: (1) impingement cooling with overboard coolant discharge, (2) impingement-film cooling, and (3) film cooling only. For this test, both of the right flaps had impingement cooling with overboard coolant discharge and both of the left flaps had impingement-film cooling with the flow discharging internally. The impingement cooled panels on the right flaps were used for obtaining the heat transfer data presented in this paper; the design details are shown in figure 5.

A photograph of the test nozzle as viewed from the exit (fig. 6) shows the impingement cooled panels installed on the right hand flaps and impingementfilm cooled panels on the left side The round to rectangular transition section can be seen upstream through the nozzle throat. The inner walls of the nozzle hot gas flowpath approximate flight weight design in order to simulate actual heat transfer conditions. A majority of the hot side wall area was $f$ abricated from Hastelloy $X$. Nozzle component wall thicknesses varied from 0.10 to $0.33 \mathrm{~cm}(0.040$ to $0.130 \mathrm{in}$.$) .$

The photo shows the position in which the nozzle was tested, that is, rotated $90^{\circ}$ about the engine centerline from a typical aircraft installation. A system of fourteen individually controlled and metered zones supplied cooling air to the various nozzle components and cooling panels.

\section{Instrumentation}

For these tests, instrumentation was provided to determine engine inlet and altitude chamber conditions, nozzle performance and engine operating status.

Engine thrust and thrust-bed preload forces were measured separately with 22240 newton (5000 ib) strain-gage load cells. The load cells were independentiy calibrated resulting in a thrust measuring system accuracy of $\pm 18 \mathrm{~N}$ $( \pm 4 \mathrm{lb})$.

A majority of pressures were recorded on 19 Scanivalves (24 ports each) that were operated by the facility computer. The differential Scanivalve transducers were calibrated while in use and had an estimated system accurracy of \pm 0.26 percent full scale. Pressures recorded with individual differential transducers had system accurracies of \pm 0.6 percent full scale.

A11 thermocouples were Chromel-Alumel type and were referenced to a $339 \mathrm{~K}$ $\left(610^{\circ} \mathrm{R}\right)$ oven. The estimated system accuracy was $\pm 1.1 \mathrm{~K}\left( \pm 2.0^{\circ} \mathrm{R}\right)$.

In total, there were approximately 150 pressure and 200 temperature sensors installed on or in the nozzle. 


\section{PROCEDURE}

\section{Performance Test}

For the dry thrust performance tests, the variable geometry nozzle was maintained in the cruise mode. The nozzle was not pivoted nor were the divergent flaps vectored differentially with respect to the nozzle centerline. Also, the thrust reverser was not utilized. The movable flaps were positioned in these tests to set a specific throat area and to vary the nozzle expansion area ratio. Nozzle dry thrust performance was recorded for three nozzle throat areas at various expansion area ratios over a range of nozzle pressure ratio. The three nominal throat areas were $710 \mathrm{~cm}^{2}\left(110 \mathrm{in.} .^{2}\right), 903 \mathrm{~cm}^{2}$ $\left(140 \mathrm{in.}^{2}\right)$, and $1129 \mathrm{~cm}^{2}\left(175 \mathrm{in.}{ }^{2}\right)$. The first area is the dry cruise throat area, the second corresponds to a partial afterburning operating point. The largest area is that required for maximum afterburning conditions. Nozzle expansion area ratio was varied from 1.2 to 2.3 . Nozzle pressure ratio test range was from 1.6 to 14.0 . The various configurations of the nozzle, as it was performance tested, are summarized in table I.

For these baseline performance tests, the nozzle throat area and expansion ratio were adjusted to the desired values. The inlet conditions were set to $10.3 \mathrm{~N} / \mathrm{cm}^{2}(15.0 \mathrm{psia})$ pressure and $289 \mathrm{~K}\left(520^{\circ} \mathrm{R}\right)$ temperature and held constant for all nozzle configurations. The nozzle cooling air zone flows were set equal to calculated design values for afterburning conditions although the test were run without afterburning. The total nozzle cooling airflow was approximately 12 percent of the nozzle exit gas flow. The nozzle inlet total temperature which is grossly a function of the nozzle throat area was set to the desired test value by small adjustments in engine speed. All data were recorded with the corrected speed above 95.5 percent to insure that the interstage compressor bleeds were closed. With the nozzle inlet total pressure fixed, the altitude chamber pressure was varied to produce the desired nozzle pressure ratio. Nozzle performance was obtained over a range of nozzle pressure ratio. Test points did not intentionally correspond to specific flight Mach number/altitude conditions.

\section{Heat Transfer Test}

Nonafterburning heat transfer data were recorded at the same time that the dry thrust performance data were recorded. In addition, the baseline thrust performance configurations $A l$ and $\mathrm{Cl}$ (table I), were pivoted to obtain the effect of convergent flap angle on the hot gas side heat transfer coefficients. Pivot vector angles up to \pm 15 degrees in 5 degree increments were used to increase the range of angle variation beyond that obtainable through throat area variation alone. By this technique, the total range of convergent flap angles to the engine centerline was varied from near zero to over 40 degrees. Also, three test conditions were selected at $5.2 \mathrm{~N} / \mathrm{cm}^{2}(7.5 \mathrm{psia})$ engine inlet pressure to extend the Reynolds number range to lower values.

\section{Post-Run Leakage Calibration}

As the nozzle tests were conducted, it became apparent from the on-line data that the level of thrust performance was substandard. It was suspected that the hot gas seals on the various movable components of the nozzle were leaking and perhaps contributing to the performance decrease. 
When altitude testing was completed a leak calibration test was performed with the nozzle and engine afterburner. The afterburner was included so as to consider possible leakage of the piston ring seal between the afterburner outlet and the nozzle inlet. Leak-tight closures were installed at the afterburner inlet and at the nozzle divergent section just upstream of the sidewall trailing edges to form a pressure vessel. For this calibration, the nozzle throat area was $710 \mathrm{~cm}^{2}\left(110 \mathrm{in.}^{2}\right)$ and the expansion area ratio was 1.2 . This configuration was chosen because it appeared to display the largest decrease in performance. And, therefore, if seal leakage contributed to the performance decline, it should be more apparent with this configuration.

The nozzle and tailpipe assembly was pressurized using the nozzle cooling air system. The total seal leakage airflow was measured with the cooling system zone flowmeters. The pressure differential imposed on the assembly was measured as the difference between the nozzle inlet total pressure rake reading and the nozzle external static pressure, which in this case was atmospheric. The assembly was calibrated over the same range of pressure differential as indicated during the nozzle performance tests by this same instrumentation. A calibration of total seal leakage airflow against imposed pressure differential was obtained. This calibration was utilized to correct the nozzle thrust performance data for the deleterious effects of the leakage.

ANALYSIS

The gross thrust coefficient of exhaust nozzles is defined as:

$$
C_{F G}=F_{G} / F_{I}
$$

The gross thrust, $F_{G}$, was determined first, by experimental measurement. The experimental thrust is obtained from the measured load cell readings adjusted for engine inlet air momentum, pressure forces, spring forces and air friction drag forces obtained from facility calibrations. In calculating the experimental thrust coefficient the ideal gross thrust, $F_{I}$, depended upon the analytical model and the data corrections assumed to account for coolant bypass flows and leakage. To obtain a gross thrust coefficient that is fully penalized for all coolant flows and leakages the ideal gross thrust was the sum of the ideal thrusts of all the individual flows entering the nozzle system. These include the engine flow and each of the fourteen separately controlled and measured external coolant supply flows. A sample set of data is shown in figure 7 where the lowest curve shows the fully penalized performance. The fully penalized curve was adjusted by the corrections for coolant bypass and leakage as explained below in detail.

The gross thrust was also calculated analytically to obtain the ideal performance at constant area ratio using simple one-dimensional, isentropic theory (dashed line in fig. 7).

Coolant bypass correction. - Some of the cooling flows were purposely discharged overboard after cooling the nozzle parts to simplify the construction of the research hardware. Specifically, the overboard flows were the aft sidewall sections which were cooled by impingement only and the right side convergent and divergent flaps which were also cooled by impingement only.

Since the overboard flow discharge was perpendicular to the surface being cooled and no attempt was made to recover thrust from the flow, the data was re-evaluated without penalizing the thrust performance for the force components of overboard flows that were perdendicular to the axial direction of 
thrust (nonaxial component). The sidewall overboard coolant discharge was always perpendicular to the engine axis and the ideal thrust of these flows were then omitted. The right convergent and divergent flaps, however, were not parallel to the engine axis and the angles varied with the throat area setting and the nozzle area ratio, $A_{e} / A_{t}$. Thus, an axial force component resulted from the discharge of coolant from the two right side flaps (fig. 5) and would effect the thrust measured by the load cells. Thus, the axial thrust components of these flows are included in the total $F_{\text {I. The nonaxial }}$ force component of these coolant flows, however, were omitted. All of the ideal thrust of the left flap coolant flows were included in the total $F_{I}$ since these flows were discharged internally.

After making the above corrections in the values of $F_{I}$, the thrust performance for the sample data set in figure 7 are shown by the square symbols which are about 1.5 percentage points above the fully penalized performance curve. This 1.5 percent represents the penalty for incomplete recovery of thrust from the externally discharged coolant which bypassed the nozzle throat.

Leakage correction. - For determining the maximum performance potential of full scale nonaxisymmetric nozzles and to compare the performance with scale model data, it was desirable to correct the data for leakage. This was particularly important for the data in this paper because the leakage was higher than would occur in a developed flight weight nozzle.

The leak flow distribution among the various seals was not measured during the leakage calibration. Qualitatively, however, it was determined during the test that the major leaks were in the region of the reverser where most of the seal length is located. A close approximation for making leakage corrections can be made by using the overall leakage calibration data.

Several assumptions were made and are summarized as follows:

1. All significant leakage occurs upstream from the nozzle throat.

2. The leakage area at hot test conditions is the same as at the ambient calibration conditions.

3. The leakage air flow properties are at local film cooling air conditions (except when the leakage is greater than the cooling air-flow rate).

4. The effective leakage areas determined from the calibration apply for all throat area and area ratio settings.

5. The leakage area is equivalent to a simple flow orifice (not a series of flow restrictions).

6. The effective leakage area is a function of only differential pressure (independent of whether the leak is subsonic or sonic flow).

When the leakage flow exceeded the cooling flow (externally supplied) some of the hot engine flow also leaks along with the cooling flow and an iterative heat balance precedure was used to obtain the temperature of the leakage flow mixture and the leakage flow rate.

Instead of separately computing and summing the ideal thrust of the individual coolant flows and the hot gas flow as was done for the initial calculation, the ideal thrust of a mixed hot gas and coolant flow through the nozzle throat was used when the data was corrected for leakage. The hot gas flow rate at the throat is adjusted for the inflow coolant and outflow leakage. The temperature of the hot gas at the throat is also adjusted for the other flows using a completely mixed model in the heat balance. An iterative solution is required. The final value of $F_{I}$ in equation (1) for this case is then the sum of the values at the throat station, the coolant flows that enter the system downstream of the throat, and the $F_{I}$ of the nonaxial components of the overboard coolant flows previously discussed. 
The top curve (circle symbols) in figure 7 is the resulting performance of the sample data set after correcting for both overboard cooling losses and leakage.

Heat transfer. - The right side convergent and divergent flaps used impingement cooling only with the coolant flow purposely discharged externally so that hot gas side heat transfer coefficients and the effect of shocks (ref. 11) thereon could be obtained with a minimum influence of film carryover. Data from the four separate panels (fig. 5) were examined to obtain the average heat transfer coefficient on both the hot gas side and the coolant side for each panel. The coolant flowrate, coolant in and coolant out temperatures were measured separately for each panel. This information along with the measured hot gas flow rates, gas temperature, and wall temperatures enabled the determination of the average heat transfer coefficients within each panel through a simple heat balance. An area weighted average of nine thermocouples on each panel was used for the wall temperature. The calculated temperature at the nozzle throat was used for the hot gas temperature in the heat balance.

The experimental heat transfer coefficients were compared with heat transfer coefficients predicted from existing correlations when available. The specific correlations used and the experimental results are discussed in the next section of the paper.

\section{RESULTS AND DISCUSSION}

Dry thrust performance. - The gross thrust coefficient data corrected for coolant bypass and leakage flows is presented in figures 8 and 9 . The thrust data are presented against nozzle pressure ratio for several nozzle area ratios at two throat areas 710 and $1129 \mathrm{~cm}^{2}$ (110 and $\left.175 \mathrm{in.}{ }^{2}\right)$. The dashed lines in the figures are the calculated ideal-expansion one-dimensional isentropic performance for each configuration assuming no coolant penalties, leakage, friction, flow angle, or nonisentropic flow effects. The solid lines in the figures are published scale model data2. The model configurations are not exactly the same (note differences in $A_{e} / A_{t}$ and the divergent flap angles, $\left.\alpha_{d}\right)$, but closely represent the full scale configurations. The configuration differences account for most of the shift in pressure ratio values where the peak performance occurs. The shifts are more pronounced at low area ratios (figs. $8(\mathrm{a})$ and $9(\mathrm{a})$ ).

The corrected $J 85$ full scale data are generally within two percent of the ideal isentropic predictions and are in good agreement with the scale model data although some scatter in the experimental data exists and the corrections for coolant bypass and leakage are not precise (see assumptions in the Analysis Section). Friction and flow angle effects can account for most of the difference between the ideal and the experimental data. The lowest experimental peak performance occurred at a high divergent flap angle (23.7 degrees in fig. $9(d))$. The low performance is due to flow angularity since a significant portion of the flow at the nozzle exit is not flowing parallel to the engine centerline. The peak performance is also lower at low area ratios $\left(A_{e} / A_{t}=1.2\right.$ in figs. $8(a)$ and $9(a)$ ) than at the mid-range area ratios. This performance loss may be attributed to three dimensional nonisentropic flow effects in the nozzle throat region which are more pronounced at the low area ratios.

Some of the corrected data at low nozzle pressure ratios show gross thrust coefficient values that are higher than the ideal isentropic (figs. 8(b), 8(c), and $9(a))$. Again, the actual flow is not ideal and the forces resulting from 
pressure recovery downstream of internal shocks can result in an increase in the total force at some nozzle pressure ratios.

The overall performance of a variable area ratio nozzle would be near the peaks of the individual fixed area ratio curves presented in figures 8 and 9 . Composite summaries of the peak performance for the two throat areas of figures 8 and 9 are presented in figures 10 and 11 , respectively. Figure 10 shows that the performance of the variable area-ratio 2D-CD nozzle at a dry cruise throat area setting is between 0.985 and 0.990 for all nozzle pressure ratios above 4.0 with the highest performance occurring at an area ratio of 1.5 . Below a nozzle pressure ratio of 4.0 , the performance decreased to a value of 0.958 at a pressure ratio of 2.5. The ideal isentropic thrust coefficient of a variable area ratio nozzle would have a value of 1.0 over the full range (a line through the peaks of the dashed lines in fig. 10). A similar plot for the maximum afterburning throat area setting (the data were obtained without afterburning) is shown in figure 11. In this case, the performance is higher than for the dry cruise configuration. The performance increased from a value of 0.967 at a pressure ratio of 2.0 to a maximum of 0.996 at a pressure ratio of 6.5 where the area ratio was 1.5. Above this pressure ratio, the maximum performance decreased slowly to a value of 0.987 at a pressure ratio of 14.0.

These high performance levels are achievable with nonaxisymmetric 2D-CD nozzles provided that the leakage and coolant penalties are eliminated.

Flow discharge coefficient. - After correcting the data for leakage and coolant flows that bypassed the nozzle throat, the flow coefficient of the nozzle was determined by ratioing the effective area of the throat to the actual measured area. The effective area was computed from the corrected values of throat flow rate and mixed hot gas temperature and the measured values of total pressure.

The flow discharge coefficients determined from the data are presented in figure 12. Above a nozzle pressure ratio of 5.0 , the flow coefficient was nearly constant for both the dry cruise throat area setting (fig. $12(a)$ ) and the maximum afterburning area setting (fig. 12(b)).

The full scale nozzle discharge coefficients are generally about two percent lower than the model data (ref. 2). The trend of the full scale nozzle values decreased at lower pressure ratios whereas the model data showed a trend toward increasing values at lower pressure ratios. The presence of seals at the nozzle throat (fig. 5) could have an effect on the flow coefficients as well as thrust performance due to a small step change in area at the throat station. The reference data was obtained with a model having continuous smooth walls and no irregular surface features or sharp corners. The discharge coefficient levels appear reasonable for these configurations and are indicative that the thrust performance shown in figures 8 and 9 are realistic and probably accurate within \pm 0.5 percent.

Wall static pressure profiles. - Typical wall centerline static pressure (ratioed to inlet total pressure) profiles for the right convergent and divergent flaps, and for the top side wall are presented in figure 13. The profiles are shown for a range of nozzle pressure ratios from below to above the ideal expansion pressure ratio (4.0) for the internal area ratio (1.2) of that particular configuration $(B-1)$. The ideal isentropic pressure ratio profile is shown by the dashed line.

Near the throat plane $\left(A_{x} / A_{t}=1.0\right)$, the sidewall centerline pressures are always above the ideal and the flap centerline pressures are always below the ideal. This indicates that a substantial nonuniform three dimensional flow field exists in the throat region. This phenomena is shown in more detail in the isometric plot of figure 14 where all the available data for the low 
nozzle pressure ratio case of figure 13 is presented for the left flaps and the top sidewall. (Left and right flap profiles were similar.) This figure indicates an inversion of the throat profile on the sidewall a short distance downstream of the throat. Although the overall pressure ratio for the test point of figure 14 was below the critical value for choked flow, some of the local static pressure levels indicated that the flow could have reached sonic velocity locally.

The basic centerline profiles along the flaps at the various nozzle pressure ratios in figure 13 are typical for any convergent-divergent nozzle whether axisymmetric or nonaxisymmetric where the pressure profiles show evidence of local shocks or pressure recovery from local overexpansion. These phenomena occur at or near the throat plane and near discontinuities in the flap walls indicated by numbered symbols in figure 13. (See fig. 6 photograph.) The data shown in figure 13 indicate a large over-expansion near the throat on the flap followed by a pressure recovery. Another pressure rise occurs further downstream on the divergent flap which could be triggered by the discontinuities. The same trends were found to exist even when the nozzle pressure ratio was raised to 6.0 , which is above the ideal expansion pressure ratio.

Figure 15 is an isometric plot of the wall static to total pressure ratio profiles for a high performance run condition. The trends are the same as for the overexpanded $c$ ase in figure 14 except that shocks are now present along the divergent flaps. The across stream pressure profiles are relatively flat across the full width of the divergent flaps except near the throat. Some drop off occurs near the edges downstream of the trailing edges of the sidewalls as would be expected at higher pressure ratios.

Even though the wall static pressure profiles show characteristics that deviate considerably from theoretical, the thrust performance remains high for most configurations. The axial component of an integration of the pressure over the surface areas would probably confirm the high thrust levels because regions of low pressure are offset in general by regions of high pressure. Such an integration was not done for the data reported because there are not enough pressure measurements for accurate results.

The effect of the nonideal pressure gradients on other performance parameters such as the cooling flows required remains to be determined.

Heat transfer coefficients. - The preliminary heat transfer data analysis completed to date for the 2D-CD research nozzle consists of determining the experimental coolant side and hot gas side heat transfer coefficients of the right side convergent and divergent flaps. These flaps are cooled by impingement only and the effects of residual cooling films from upstream are small. (Most of the upstream cooling flows leaked through the seals.) The majority of the experimental heat transfer data were obtained with configurations Al and $\mathrm{Cl}$ (table I). Three test conditions run at half atmosphere engine inlet pressure were included to extend the Reynolds number range to lower values.

Impingement cooling. - The coolant side heat transfer coefficients obtained experimentally are compared with values predicted using the method of Kercher and Tabakoff (ref. 12) in figure 16. Most of the experimental data is within \pm 15 percent of the predicted values. The greatest deviation occurred for data from the third panel (RDF3) located furthest downstream. This could be the result of small differences in the panel construction or experimental error since the coolant exit temperature was the average of only two thermocouple measurements.

Since only the average experimental heat transfer coefficients were obtainable for each impingement panel, the calculation for predicted heat trans- 
fer coefficients were also the average for each panel. That is, the cross flow effects were determined by using a single average value of the cross flow parameter in the reference (ref. 12). The flow rate distribution among the 246 holes in each panel was assumed uniform and property values were determined at the average of the coolant in and wall temperatures. The diameter Reynolds number range was $4.0 \times 10^{3}$ to $1.5 \times 10^{4}$.

Supersonic hot gas heat transfer. - The hot gas side heat transfer coefficients were computed from the average bulk to wall temperature differences for each cooling panel and the heat flux from the temperature rise of the coolant. The data are plotted in figure 17 as a function of hydraulic diameter of the flow path between the two divergent flaps and also compared with predicted values on the right side of the figure. The data covered a range of Reynolds number from $7.0 \times 10^{5}$ to $2.0 \times 10^{6}$ computed on a hydraulic diameter basis and film property values were determined from the average of hot gas bulk and wall temperatures. The equations used for the predicted values are discussed in McAdams (ref. 13) for high $\Delta t$ gases:

$$
N u=\frac{h D_{H}}{K_{f}}=0.023 \operatorname{Re}_{f}^{0.8} \operatorname{Pr}^{0.4}
$$

where

$$
\operatorname{Re}_{f}=\frac{D_{H} V_{\rho_{f}}}{\mu_{f}}
$$

The experimental values are as much as 40 percent higher than predicted at the higher heat transfer rates. An attempt was made to achieve a better agreement with an equation for high speed flows (ref. 14) where a reference temperature and a flat plate length Reynolds number was used. The results were even less satisfactory. It is apparent from these data that a more rigorous analytical approach is needed to improve the predictions which should include the effects of shocks (ref. 11).

Accelerating subsonic heat transfer. - When the standard equation (2) was used for predicting heat transfer on the converging $f l a p$, the correlation was poor. Significant variations of heat transfer coefficient occured with change in the angle of the convergent flap to the hot gas stream. The data were plotted as a function of flap angle in figure 18 where it grouped about a single line. The empirically derived equation for the line shown is:

$$
N u_{b}=0.023 \operatorname{Re}_{b}^{0.8} \operatorname{Pr}^{0.4}\left(1+\frac{\alpha_{c}^{0.8}}{15}\right)
$$

This equation is the standard equation (2) with the addition of a term containing the angle of the flap relative to the hot gas flow direction entering the convergent portion of the nozzle (fig. 5). The form of the added term was chosen such that when the flap angle is zero (parallel to the hot gas flow) the equation reduces to the form of equation (2). No attempt has been made to date to explain the results analytically.

Leakage reduction. - Nonaxisymmetric nozzles have the potential for high thrust performance provided that leakage losses can be minimized. The experi- 
ence obtained to date indicates this could be a problem. Some suggested design philosophies for reducing leakage are listed in figure 19. A suggested design concept utilizing the philosophies is shown conceptually in figure 20. Most of the requirements for nonaxisymmetric nozzles including vectoring and reversing functions are included.

Figure 21 presents one possible seal design approach. Simple leaf type seals are shown at edges of the convergent flap and at the flap hinge cylinder arranged such that a moveable seal strip engages another fixed seal strip at the ends of travel to provide a more positive shut off of the leak flow path during dry cruise (non $A / B$ ) and maximum $A / B$ positions which exist for most of the operating time during flight. Also note that the seals at both of the hinges on the convergent flap are located outside of the hot gas flow path where cooler temperatures exist. This should minimize warpage due to thermal stresses.

\section{SUMMARY OF RESULTS}

An aircooled nonaxisymmetric 2D-CD research exhaust nozzle was tested on a J85 turbojet engine in an altitude test facility over a range of nozzle pressure ratios from 1.6 to 14.0. Dry baseline axial thrust performance and heat transfer characteristics were determined for three nozzle throat areas and a range of area ratios from 1.2 to 2.3. The data analysis included corrections in the performance for cooling airflows that bypassed the nozzle throat and seal leakages. The corrected thrust data were compared with theory and scale model data. The heat transfer data were compared with predicted values. The significant results were as follows:

1. Above a nozzle pressure ratio of 4.0 , the peak corrected gross thrust coefficient was 0.985 or higher for all configurations except for one high divergence angle configuration.

2. The corrected thrust data were in good agreement with one-dimensional theory and scale model data over the full range of nozzle pressure ratio for most configurations. The poorest agreement occurred at a high 23.7 degree, divergent flap angle (up to 4 percent below ideal) and for low area ratio configurations ( 2 percent below ideal).

3. Static wall pressure profile data indicated that strong three dimensional flow effects occurred near the throat plane and along the divergent flaps near wall surface discontinunities. These flow effects were more pronounced than occurred in scale models.

4. The magnitude of the data corrections indicated that substantial thrust penalties could result from coolant bypass flow and leakage.

5. Coolant side heat transfer coefficients were in acceptable agreement with predictions. Additional analytical work is needed, however, to improve the predictability of the hot gas side heat transfer on both the convergent and divergent flaps so that adequate cooling can be provided.

\section{REFERENCES}

1. Capone, F. J., "A Review of Nonaxisymmetric Nozzle technology applied to Twin Engine Aircraft," AIAA Paper 79-1810, Aug. 1979.

2. Berrier, B. L., and Re, R. J., "Effect of Several Geometric Parameters on the Static Internal Performance of Three Nonaxisymmetric Nozzle Concepts," NASA TP-1468, 1979. 
3. Re, Richard J., and Berrier, Bobby L., "Static Internal Performance of Single Expansion-Ramp Nozzle With Thrust Vectoring and Reversing." NASA TP-1962, 1982.

4. Mason, M. L., Putnam, L. E., and Re, R. J., "The Effect of Throat Contouring on Two-Dimensional Converging-Diverging Nozzles at Static Conditions," NASA TP-1704, 1980.

5. Yetter, J. A., and Leavitt, L. D., "Effects of Sidewall Geometry on the Installed Performance of Nonaxisymmetric ConvergentDivergent Exhaust Nozzles," NASA TP-1771, 1980.

6. Hutchinson, R. A., Petit, J. E., Capone, F. J., and Sevigny, E. G., "Investigation of Advanced Thrust-Vectoring Exhaust Systems for High Speed Propulsive Lift," AIAA Paper 80-1159, July 1980.

7. Capone, F. J., "Aeropropulsive Characteristics of Twin Nonaxisymmetric Vectoring Nozzles Installed with Forward-Swept and Aft-Swept Wings in the Langley 16-foot Transonic Tunnel," NASA TP-1778, 1981.

8. Capone, F. J., Hunt, B. L., and Poth, G. E., "Subsonic/Supersonic Nonvectored Aeropropulsive Characteristics of Nonaxisymmetric Nozzles Installed on an F-18 Mode1," AIAA Paper 81-1445, July 1981.

9. Bare, A. E., Berrier, B. L., and Capone, F. J., "Effect of Simulated InFlight Thrust Reversing on Vertical-Tail Loads of F-18 and F-15 Airplane Models - conducted in the Langley 16-foot Transonic Tunnel, "NASA TP-1890, 1981.

10. Nash, D. 0., Wakeman, T. G., and Palcza, J. L., "Structural and Cooling Aspects of the ADEN Nonaxisymmetric Exhaust Nozzle," ASME Paper 77-GT-110, 1977.

11. Straight, D. M., "Effect of Shocks on Film Cooling of a Full Scale Turbojet Exhaust Nozzle Having an External Expansion Surface," AIAA Paper 79-1170, June 1979.

12. Kercher, D. M., and Tabakoff, W., "Heat Transfer by a Square Array of Round Air Jets Impinging Perpendicular to a Flat Surface Including the Effect of Spent Air," Journal of Engineering for Power, Vol. 92, Jan. 1970, pp. 73-82.

13. McAdams, W. H., Heat Transmission, 3rd ed., McGraw-Hi11, Inc., New York, 1954, pp. 221-222.

14. Eckert, E. R. G., "Engineering Relations for Heat Transfer and Friction in High-Velocity Laminar and Turbulent Boundary-Layer Flow Over Surfaces With Constant Pressure and Temperature," Trans. ASME, Vol. 78, Aug. 1956, pp. 1273-1283. 
TABLE I. - NOZZLE CONF IGURATION

\begin{tabular}{|c|c|c|c|c|c|c|}
\hline \multirow[t]{2}{*}{$\begin{array}{c}\text { Configuration } \\
\text { designation }\end{array}$} & \multicolumn{2}{|c|}{$\begin{array}{c}\text { Nozzle throat } \\
\text { area, } A_{t}\end{array}$} & \multirow{2}{*}{$\begin{array}{c}\text { Nozzle } \\
\text { area } \\
\text { expansion } \\
\text { ratio } \\
A_{e} / A_{t}\end{array}$} & \multirow{2}{*}{$\begin{array}{l}\text { Nozzle } \\
\text { throat } \\
\text { aspect } \\
\text { ratio }\end{array}$} & \multirow{2}{*}{$\begin{array}{c}\text { Convergent } \\
\text { wall } \\
\text { angle } \\
\alpha_{c}, \\
\text { deg }\end{array}$} & \multirow{2}{*}{$\begin{array}{c}\text { Divergent } \\
\text { wall } \\
\text { angle } \\
\text { ad, } \\
\text { deg }\end{array}$} \\
\hline & $\mathrm{cm}^{2}$ & in. ${ }^{2}$ & & & & \\
\hline Al & 707.1 & 109.6 & 1.20 & 4.10 & 28.75 & 2.19 \\
\hline A2 & & & 1.50 & & & 5.66 \\
\hline$A 3$ & & & 1.79 & & & 8.87 \\
\hline A4 & & & 2.29 & & & 14.60 \\
\hline BI & 902.0 & 139.8 & 1.20 & 3.19 & 21.35 & 2.86 \\
\hline $\mathrm{Cl}$ & 1130.4 & 175.2 & 1.20 & 2.55 & 13.15 & 3.58 \\
\hline $\mathrm{C} 2$ & & & 1.50 & & & 8.91 \\
\hline $\mathrm{C} 3$ & & & 1.80 & & & 14.31 \\
\hline C4 & & & 2.30 & & & 23.72 \\
\hline
\end{tabular}




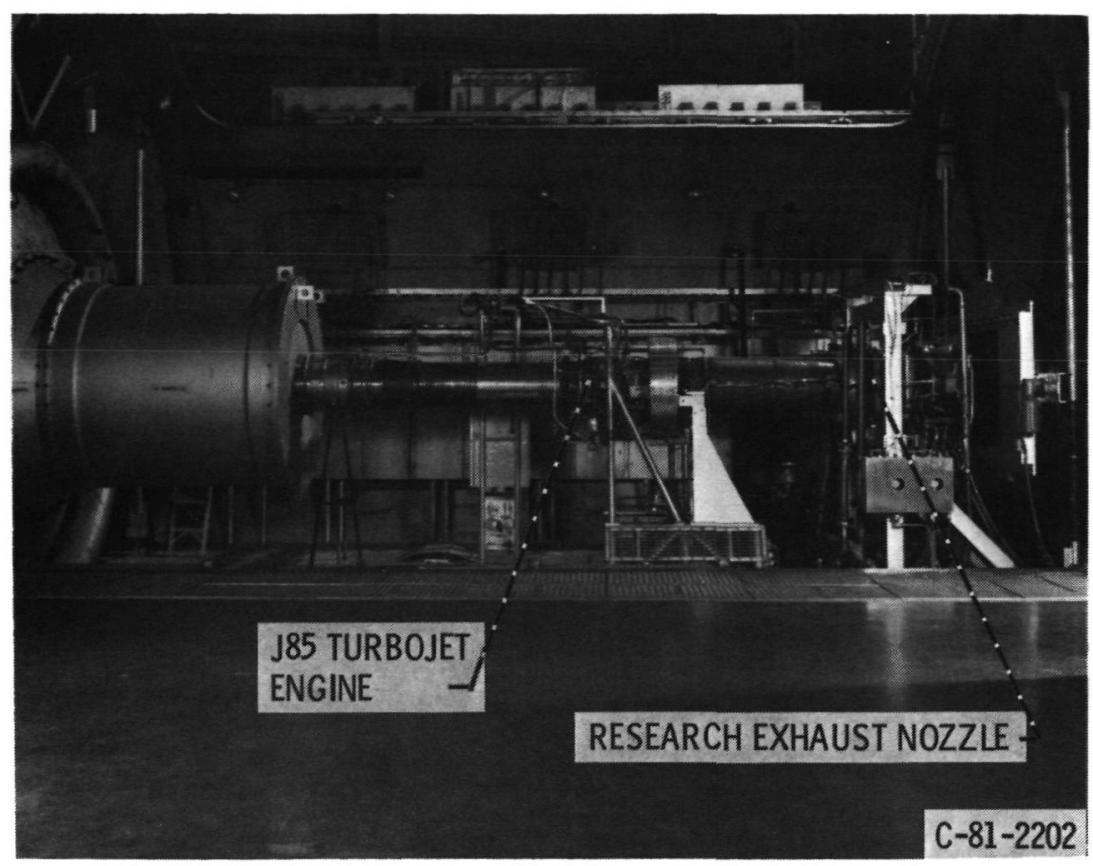

Figure 1. - Engine installation in altitude test chamber.

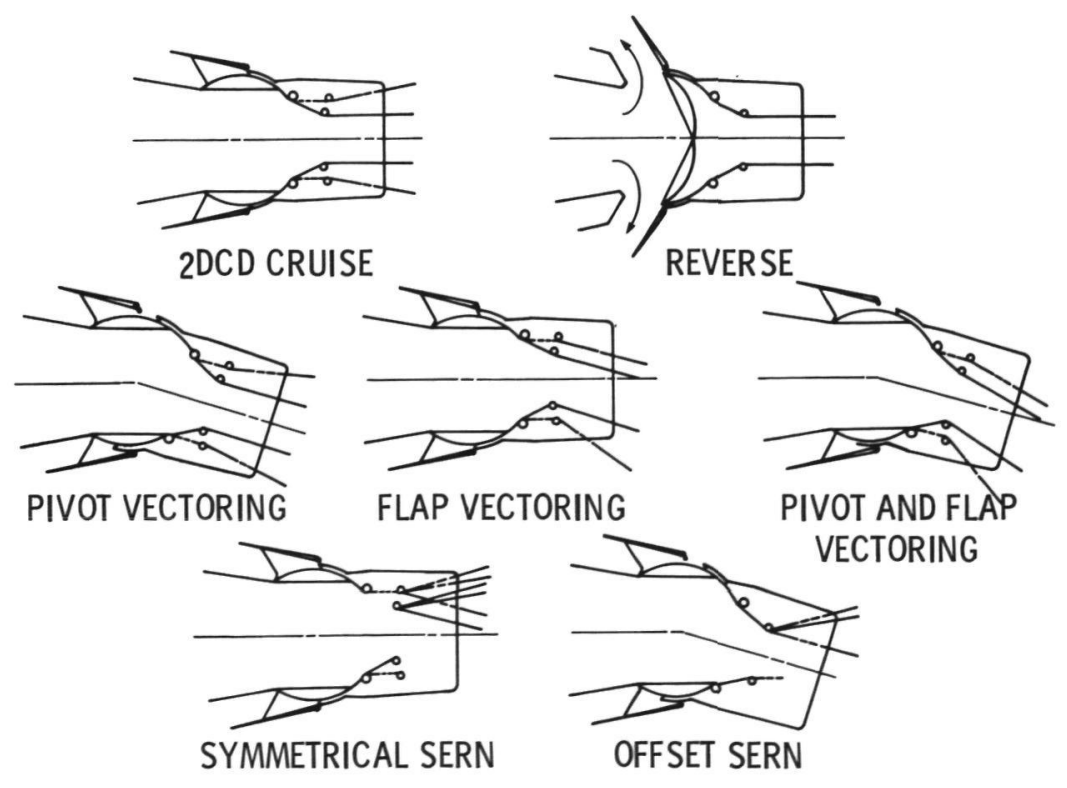

Figure 2. - Sketches of nonaxisymmetric research nozzle showing aeroflowpath versatility. 


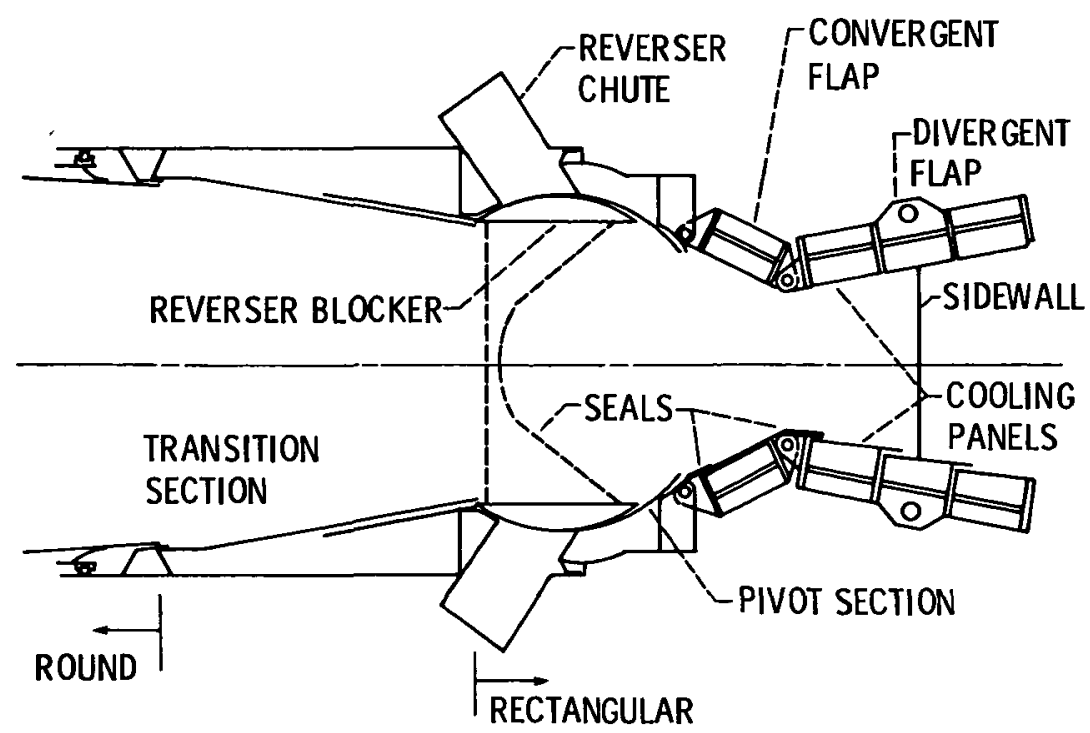

Figure 3. - Schematic of J85 2DCD research exhaust nozzle.

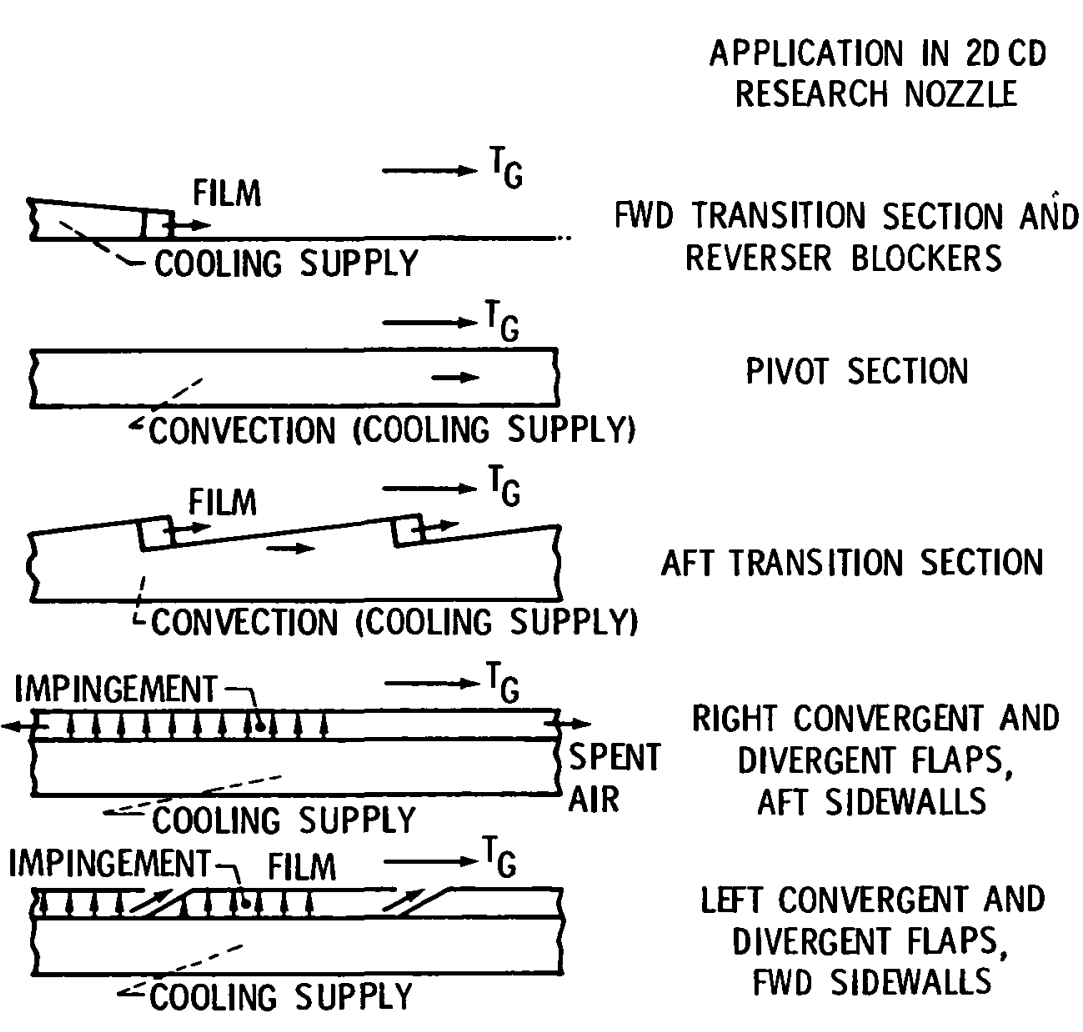

Figure 4. - Cooling methods used in $\mathrm{J} 85$ research nozzle. 


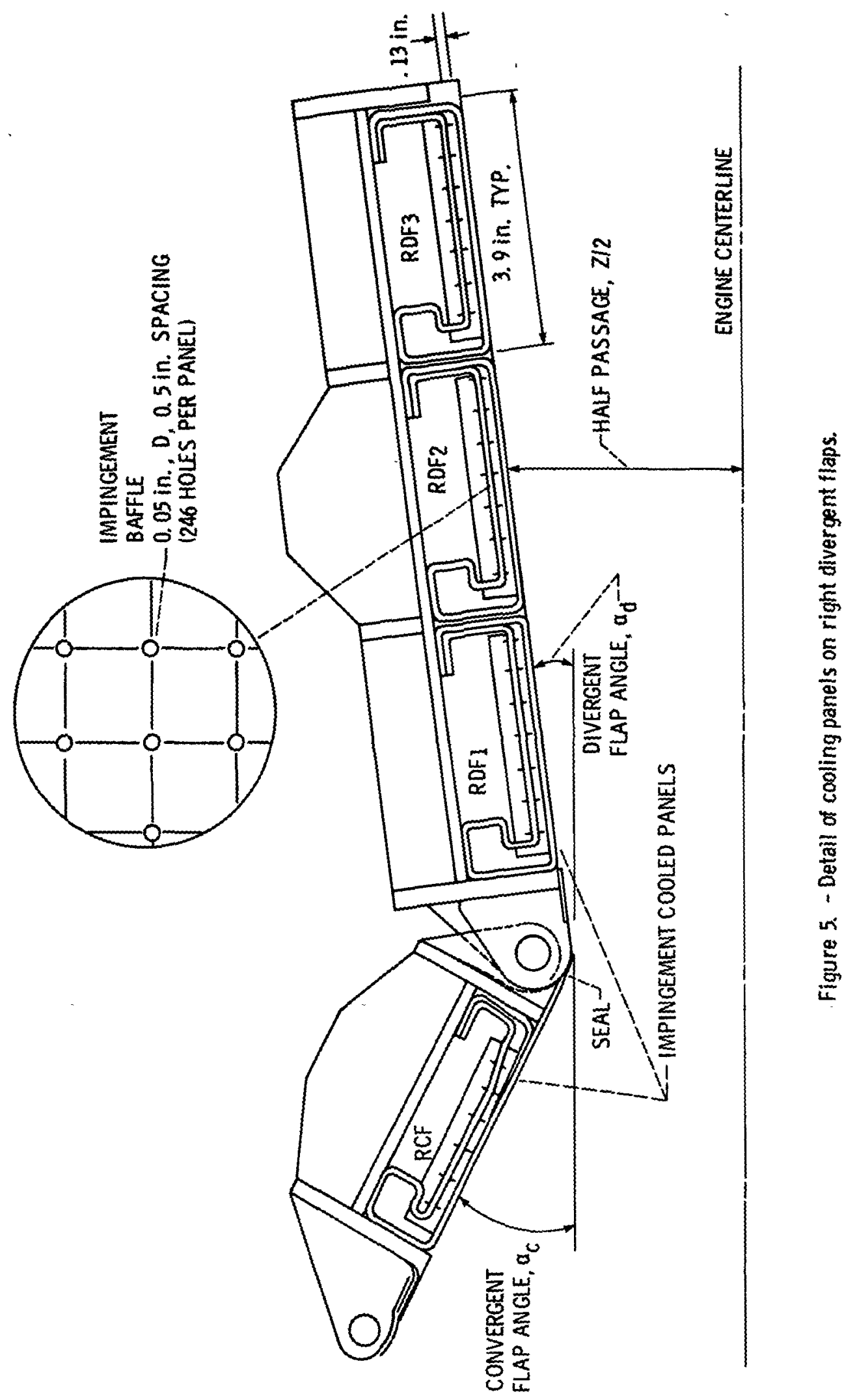




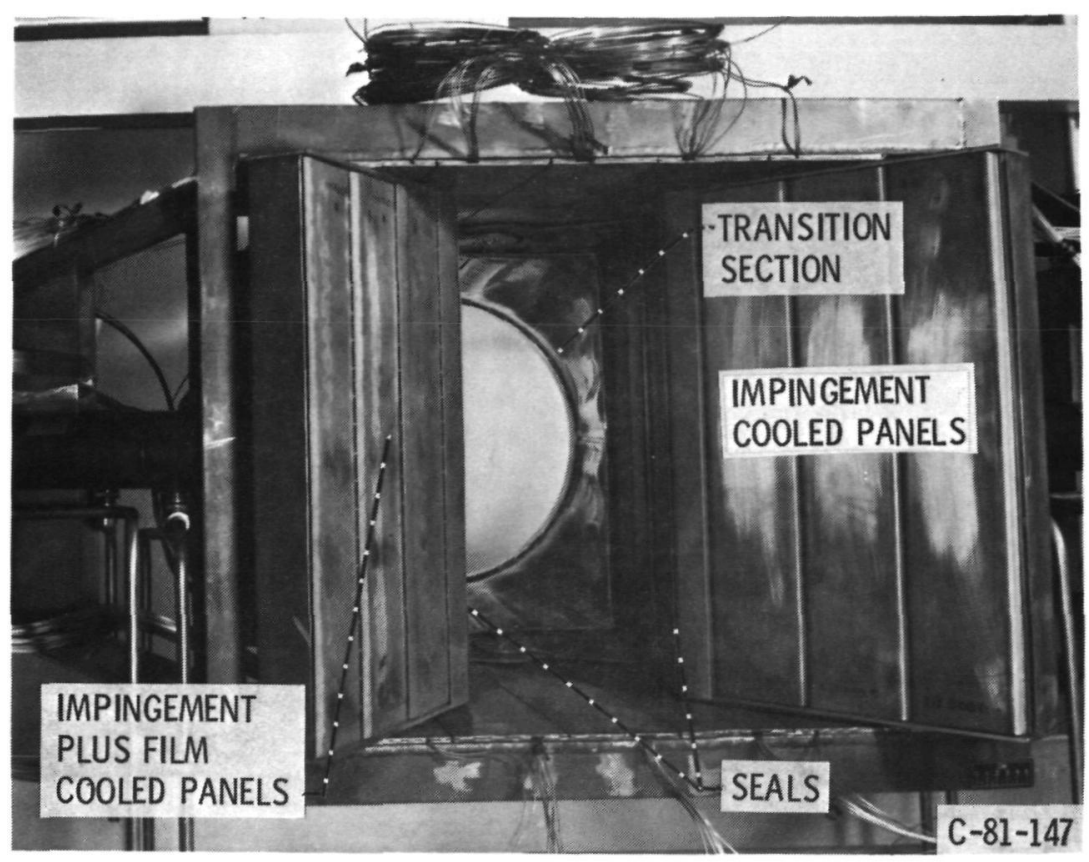

Figure 6. - Exit view photograph of J85 2DCD research exhaust nozzle.

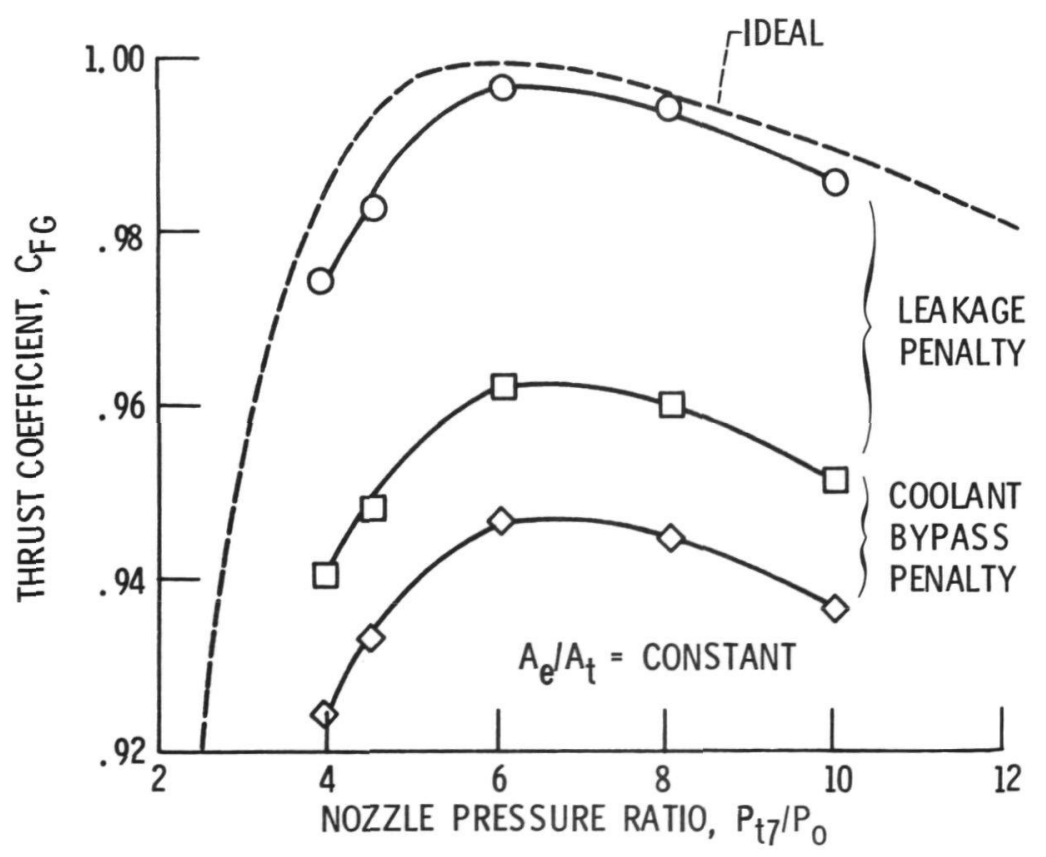

Figure 7. - Typical corrections to J85 2DCD experimental data to account for coolant bypass flows and leakage. 

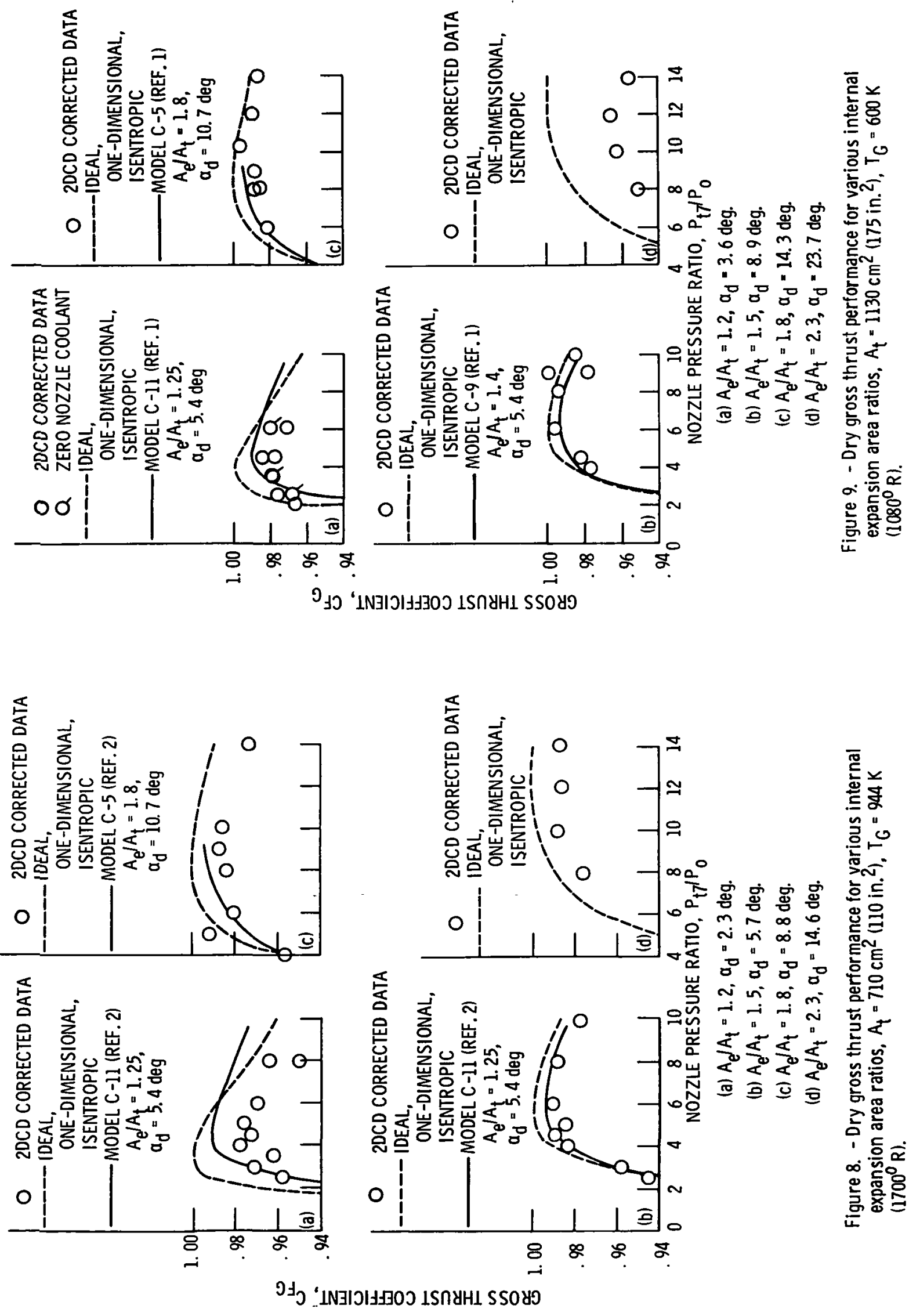


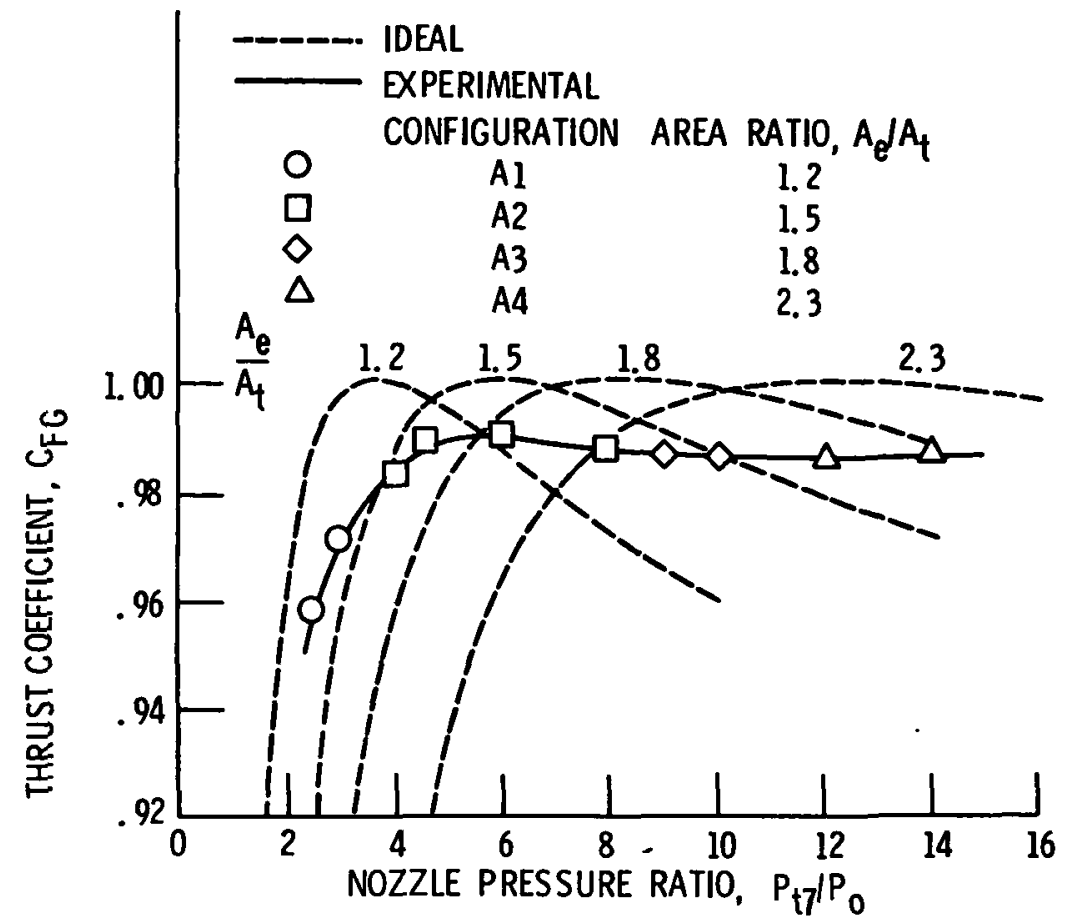

Figure 10. - Dry gross thrust performance summary of J85 2DCD research nozzle, $A_{t}=710 \mathrm{~cm}^{2}\left(110 \mathrm{in} .{ }^{2}\right)$, $T_{G}=944 \mathrm{~K}\left(1700^{\circ} \mathrm{R}\right)$.

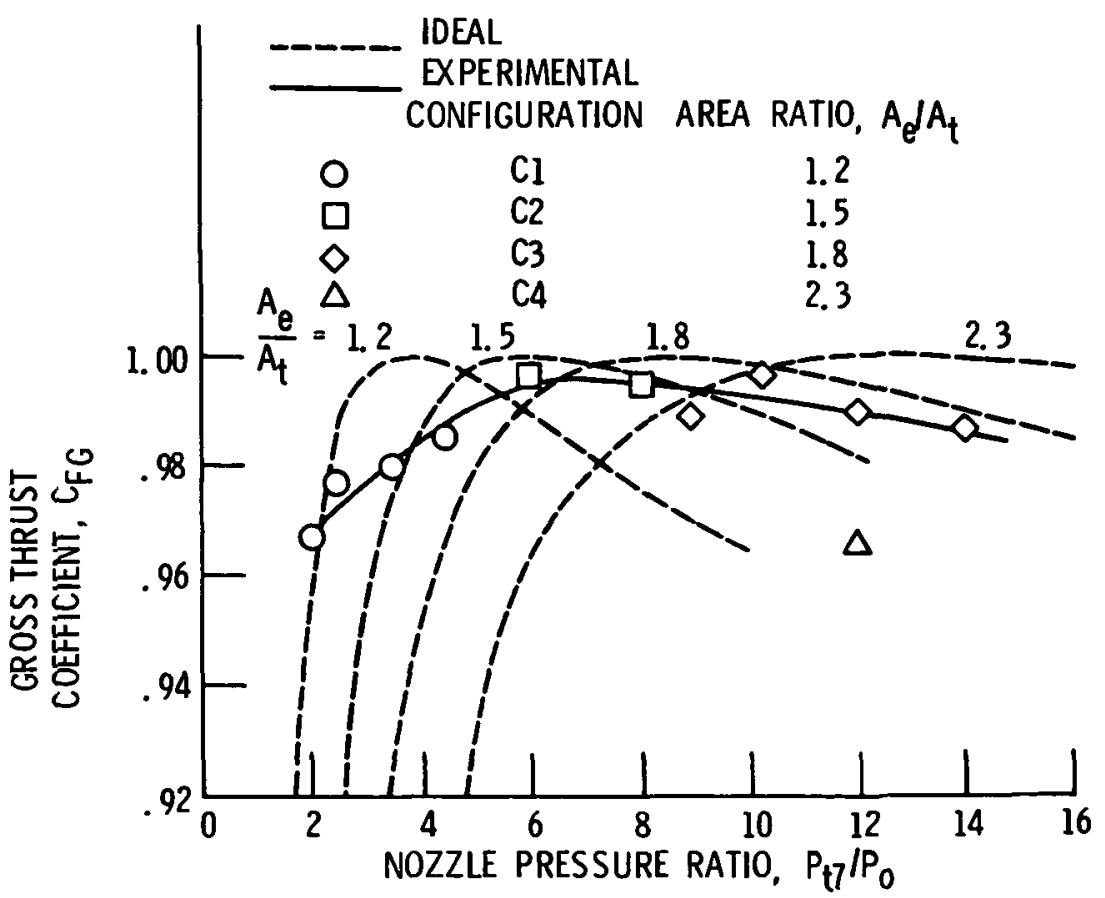

Figure 11. - Dry gross thrust performance summary of $\mathrm{J} 85$ $2 D C D$ research nozzle, $A_{t}=1130 \mathrm{~cm}^{2}\left(175 \mathrm{in.}^{2}\right), \mathrm{T}_{G}=$ $600 \mathrm{~K}\left(1080^{\circ} \mathrm{R}\right)$. 

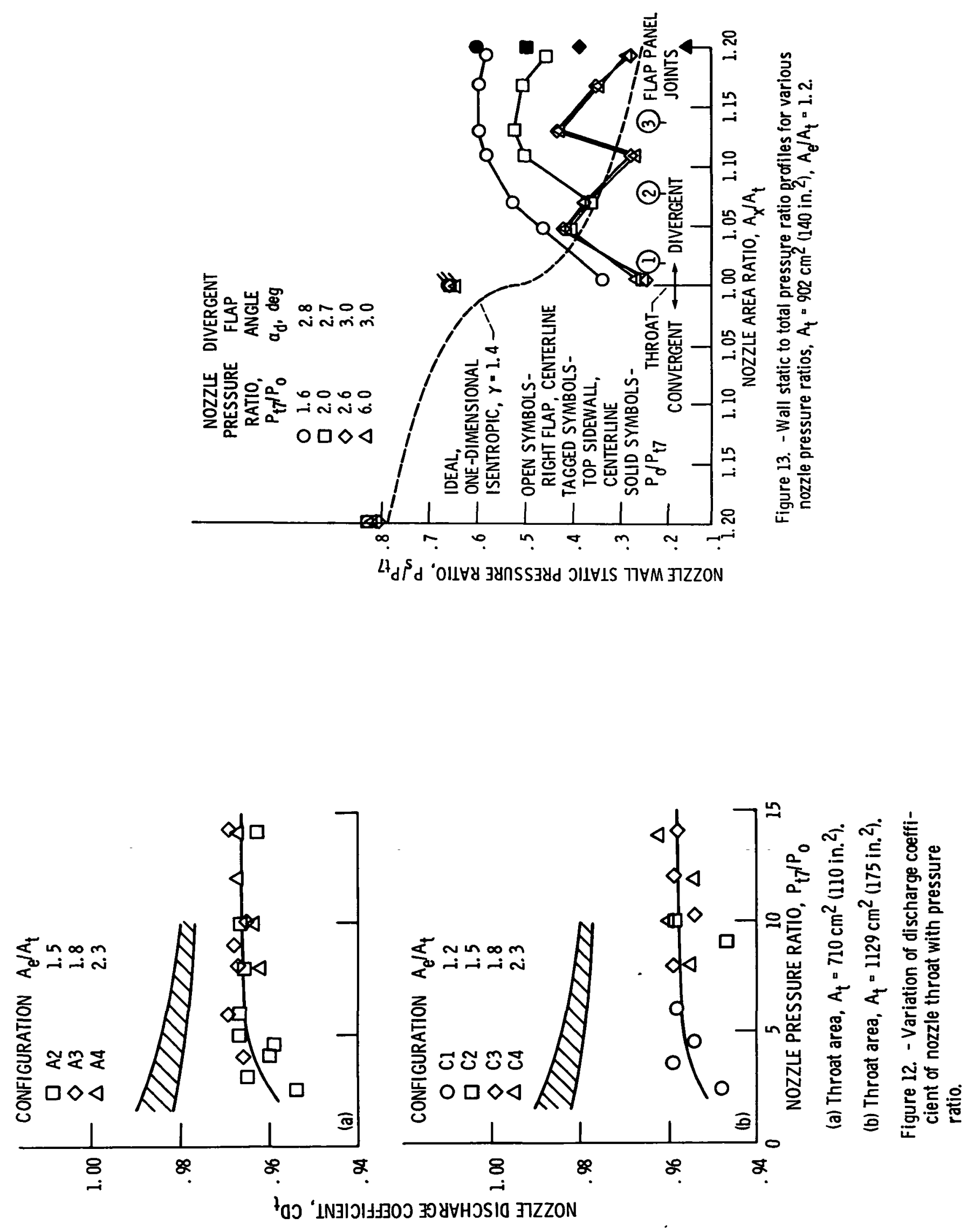

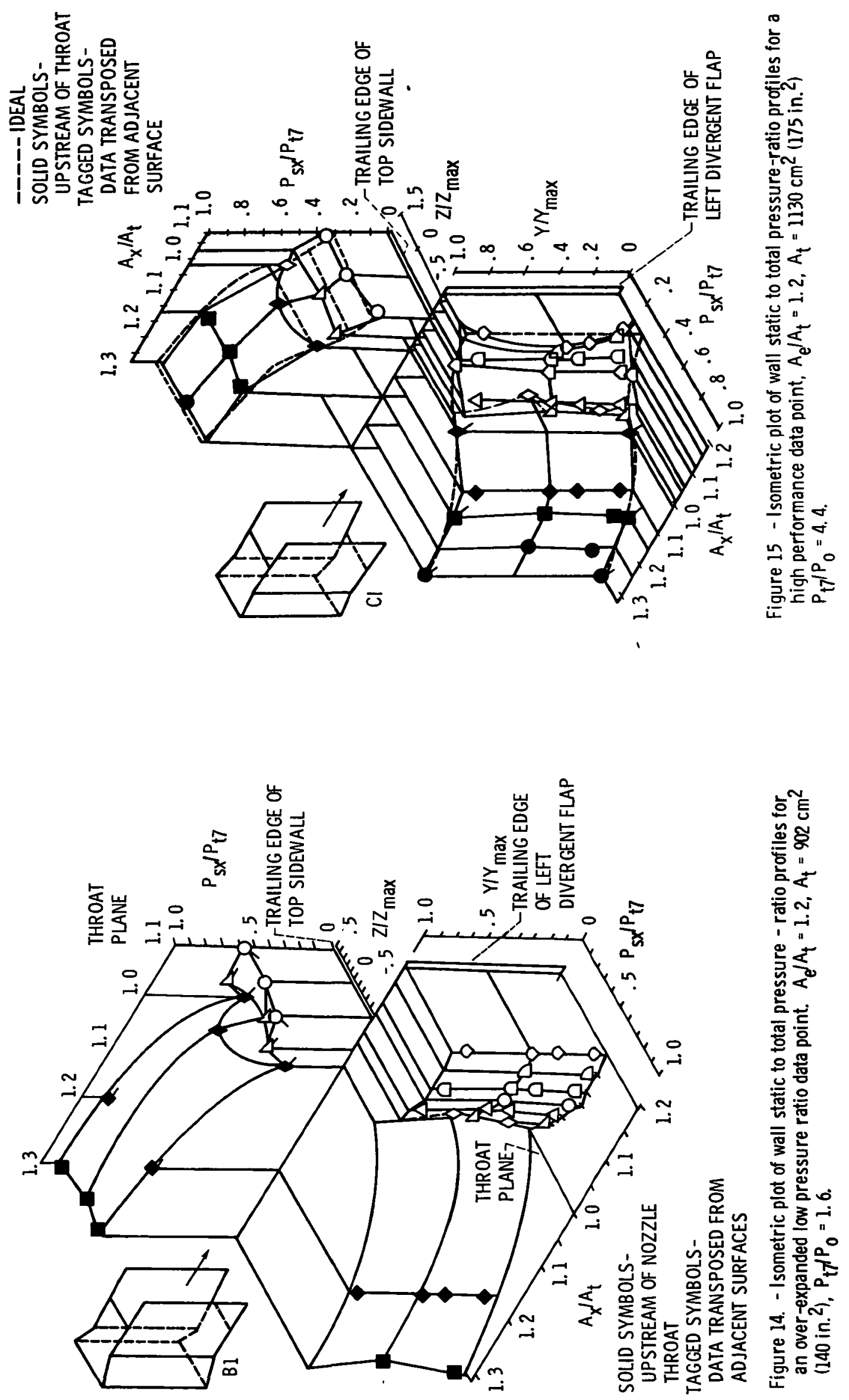


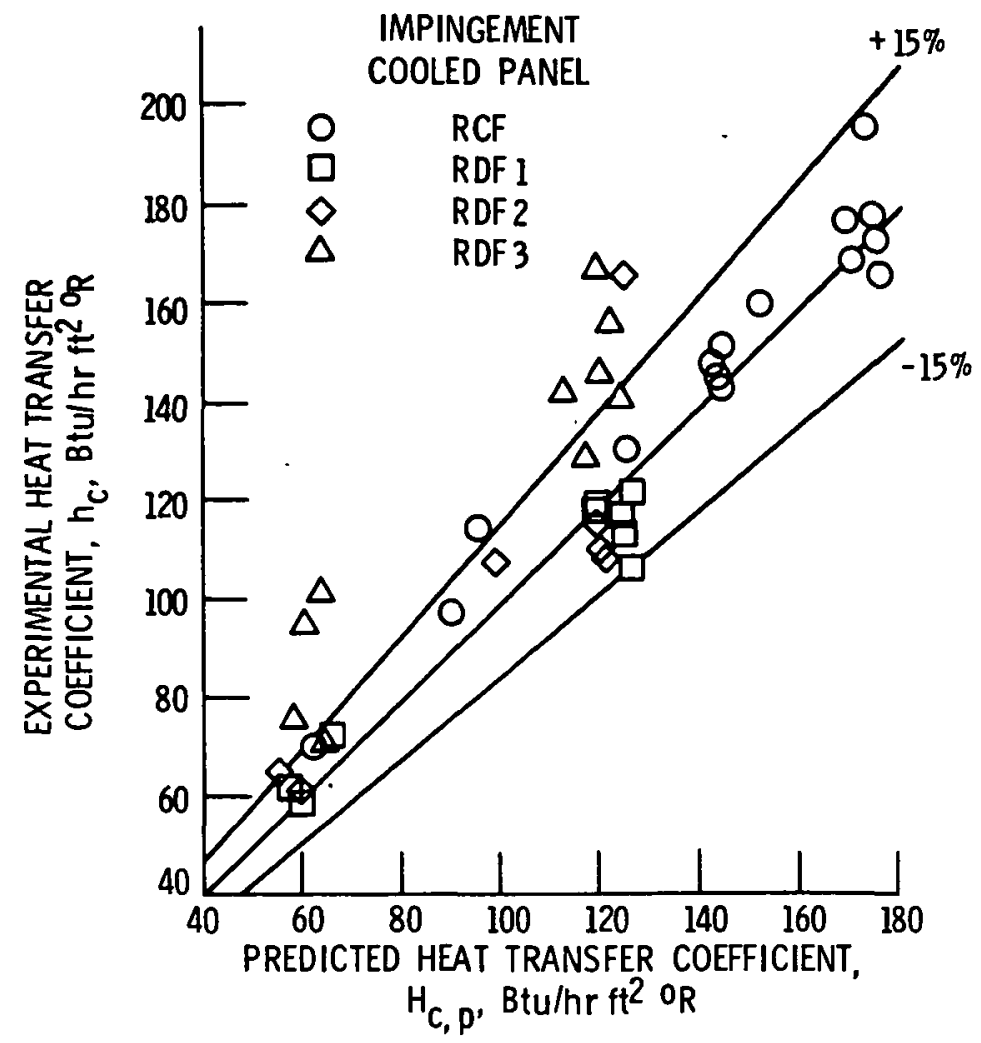

Figure 16. - Comparison of experimental with predicted impingement cooling heat transfer coefficients per method of reference 12.

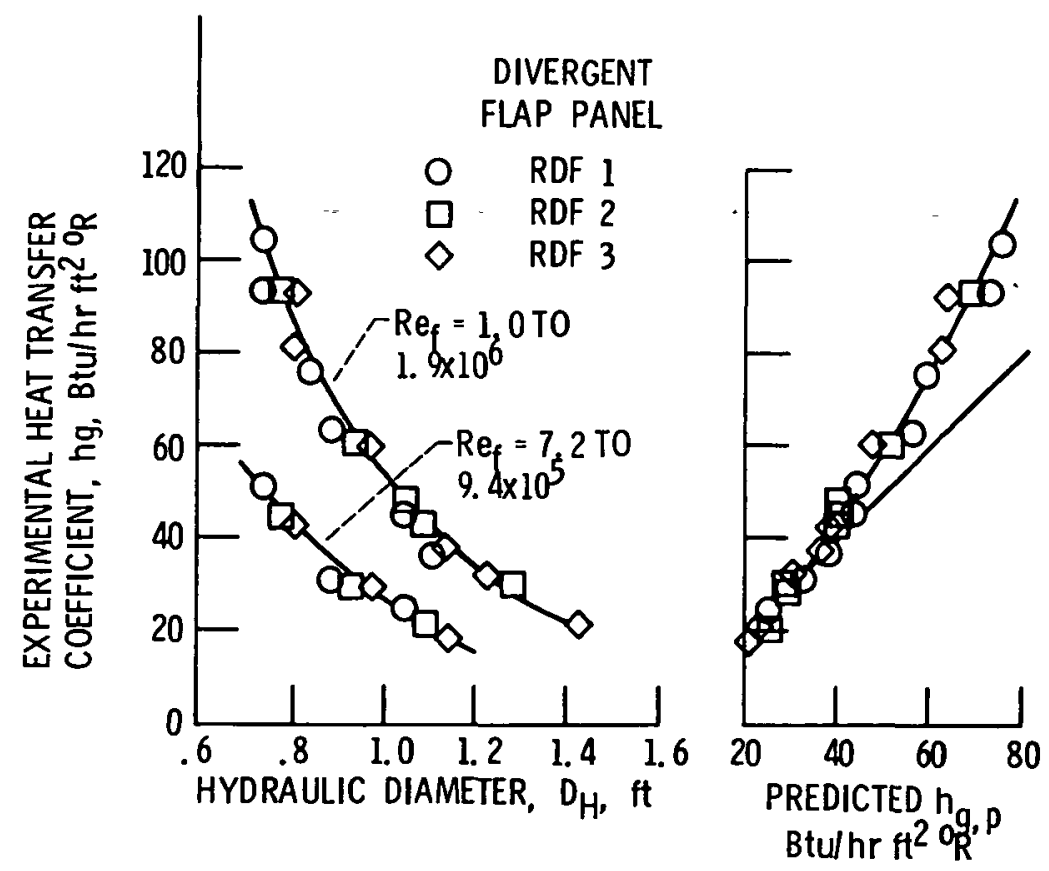

Figure 17. - Experimental supersonic hot gas heat transfer coefficients on right divergent flaps and comparison with predictions. 


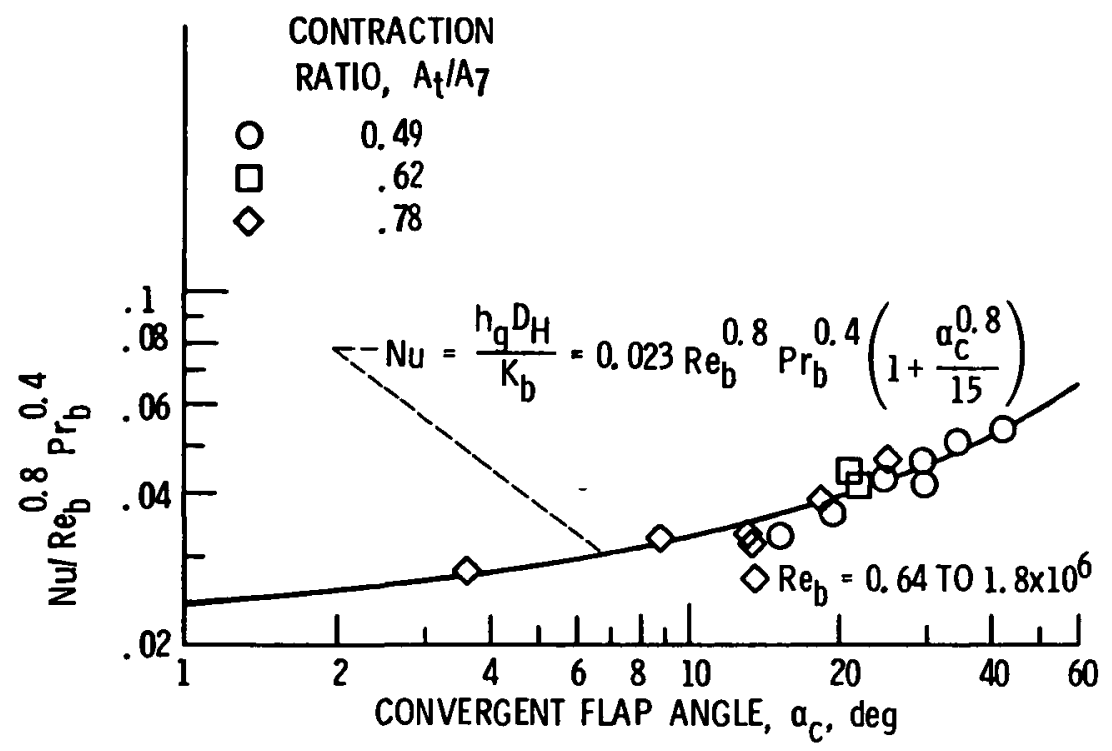

Figure 18. - Heat transfer correlation including the effect of converging flap angle in accelerating hot gas flow.

1. LOCATE SEALS DOWNSTREAM OF THROAT WHEN POSSIBLE.

A) THRUST REVERSER
B) VECTORING FLAPS

2. POSITIVE SHUT OFF OF LEAKS AT MINIMUM THROAT AREA (DRY CRUISE) AND AT MAXIMUM THROAT AREA (MAX. A/B).

3. SEALS PROTECTED FROM HOT GAS TO PREVENT WARPAGE DUE TO THERMAL STRESSES.

4. REDUNDANT SEALS, I.E., DOUBLE OR TRIPLE SEALING.

5. MINIMUM LENGTH SEALS UPSTREAM OF THROAT.

Figure 19. - Suggested design philosophies for reducing seal leakages in nonaxisymmetric exhaust nozzles. 

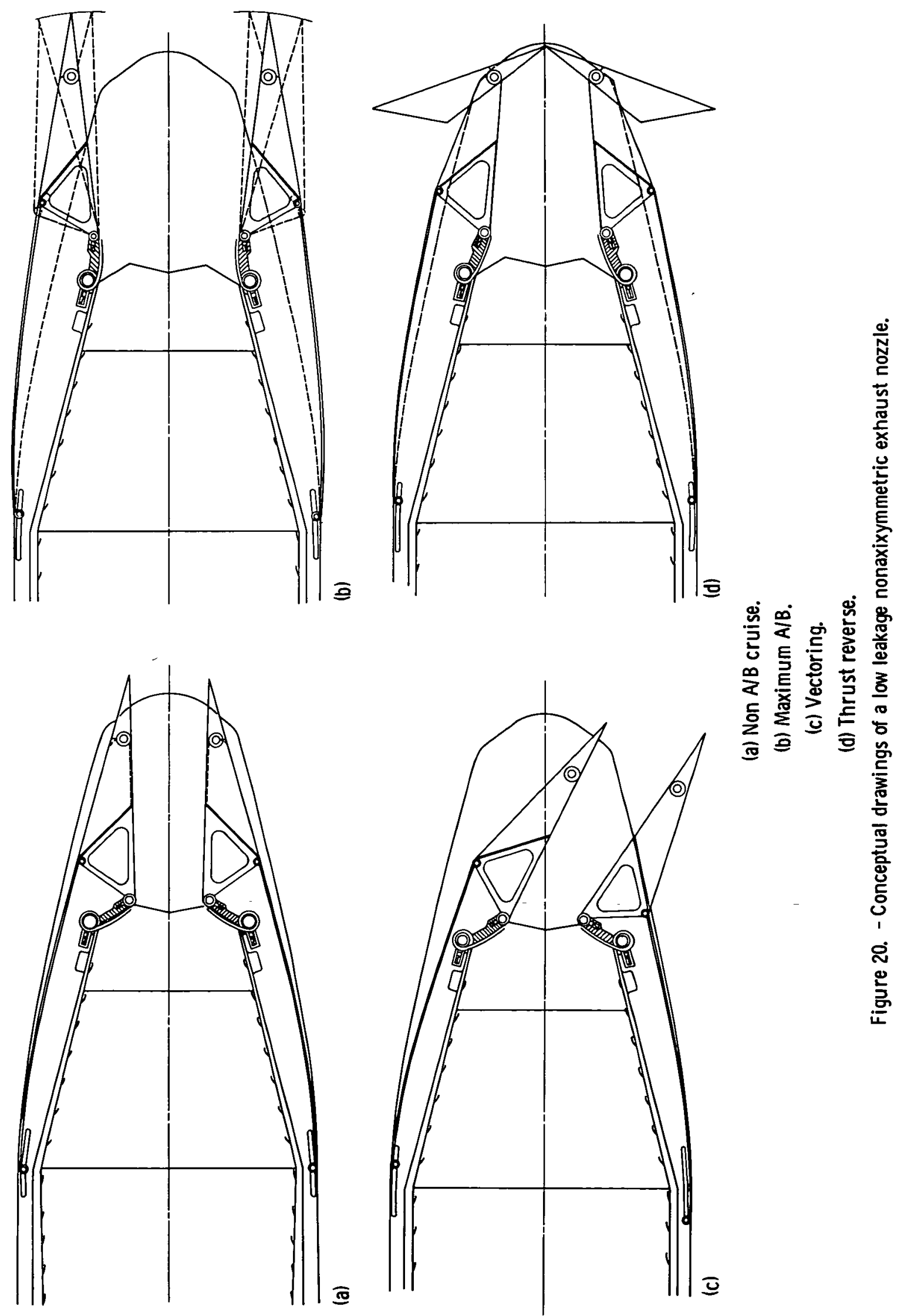


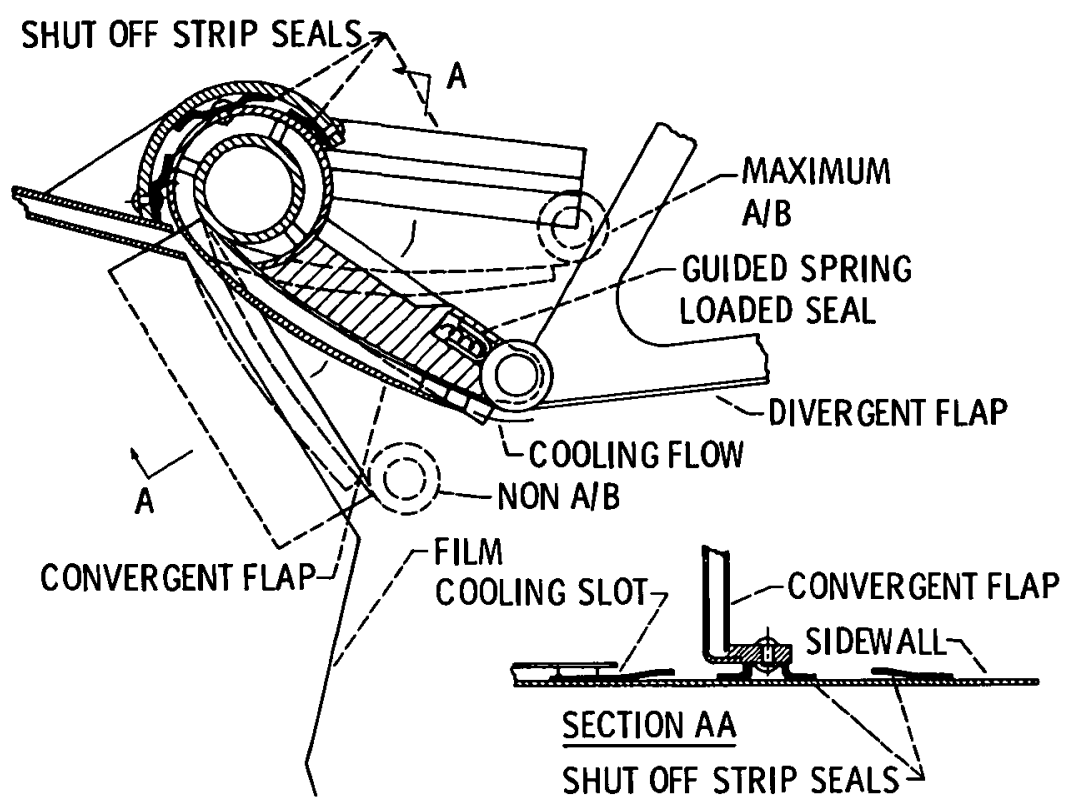

Figure 21. - Conceptual drawing of low leakage seal designs. 


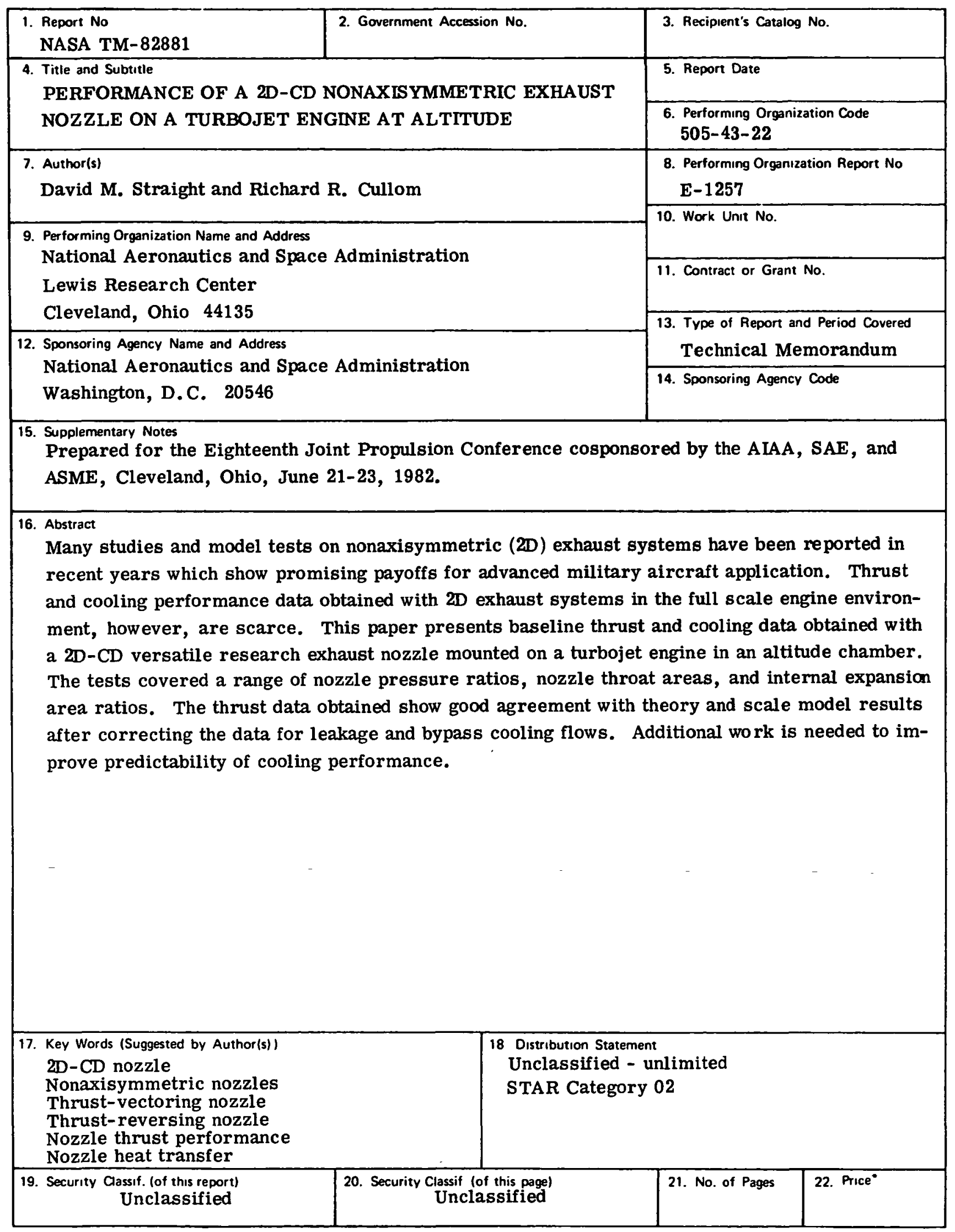

* For sale by the National Technıcal Information Service, Sprıngfıeld, Vırgınia 22161 
National Aeronautics and Space Administration

Washington, D.C.

20546

Official Business

Penalty for Private Use, $\$ 300$
SPECIAL FOURTH CLASS MAIL BOOK

Space Administration

NASA.451 